'Departamento de Ciencias Neurológicas Oriente. Hospital del Salvador. Facultad de Medicina, Universidad de Chile. Santiago, Chile.

2Unidad de Hematología Intensiva. Departamento de Medicina Oriente Hospital de Salvador. Facultad de Medicina, Universidad de Chile. Santiago, Chile.

Los autores declaran no tener conflictos de interés. Trabajo no recibió financiamiento.

Recibido el 29 de diciembre de 2017, aceptado el 27 de junio de 2018.

Correspondencia a: Luis Cartier Rovirosa Av. Salvador 364, Providencia, Santiago, Chile. Icartier@med.uchile.cl

\section{Síndrome de degeneración combinada de la médula espinal y radiculopatía en dos pacientes por quimioterapia intratecal con metrotrexato y citarabina. Casos clínicos}

\author{
LUIS CARTIER R. ${ }^{1}$, JORGE PARRA V. ${ }^{1}$, \\ BÁRBARA PUGA ${ }^{2}$, DANIELA CARDEMIL ${ }^{2}$
}

\section{Spinal subacute combined degeneration after intrathecal chemotherapy. Report of two cases}

Intrathecal chemotherapy may be complicated with the development of myelopathies or toxic radiculopathies. This myeloradicular involvement, of toxic character, is unpredictable, since these patients have repeatedly received Intrathecal chemotherapy with the same drugs without apparent injury. The toxic effect should be mainly attributed to Cytarabine and not to methotrexate, since the central nervous system lacks Cytidine deaminase, the enzyme that degrades Cytarabine. We report two patients, an 18-year-old woman and a 16 years old male, who received systemic and intrathecal chemotherapy (methotrexate, cytarabine) for the treatment of an acute lymphoblastic leukemia and developed, in relation to this procedure, a spinal subacute combined degeneration. They had a proprioceptive and motor alteration of the lower extremities and neuroimaging showed selective rear and side spinal cord hyper intensity produced by central axonopathy. Two weeks later the woman developed a quadriplegia and the young man a flaccid paraplegia due to added root involvement.

(Rev Med Chile 2018; 146: 802-807)

Key words: Cytarabine; Drug Therapy; Meningeal Neoplasms; Subacute Combined Degeneration.

\section{L} a triple asociación de Metrotrexato, Citarabina y Betametazona es un esquema habitual en la quimioterapia intratecal (QI), usada de manera profiláctica, o en el tratamiento de Leucemias Linfoblásticas agudas (LLA) ${ }^{1}$. Esporádicamente, desde la implementación de la QI, se han comunicado casos de mielopatías tóxicas asociadas a este tipo de tratamiento ${ }^{2}$. Se sabe que la inoculación intratecal de Citarabina y Metrotrexato producen una rápida impregnación de la médula espinal y de las raíces nerviosas, basados en estudios de animales de laboratorio, cuyas autorradiografías expresan una saturación que va del
$67 \%$ al $99 \%$ en la primera hora ${ }^{3}$. Esta característica ha permitido que esta quimioterapia sea mayoritariamente exitosa, aunque eventualmente capaz de producir alteraciones de la médula espinal semejantes al "Síndrome de degeneración combinada subagudo de la médula espinal" ${ }^{4,5}$, mielopatía que se desarrolla rápidamente, iniciando desde el día siguiente a pocos días después de la última administración y que no está relacionado con el número de pulsos, ni con las dosis totales usadas ${ }^{5-7}$.

La Citarabina usada en dosis máximas tiene una reconocida toxicidad sobre el Sistema Nervioso Central (SNC), siendo capaz de desarrollar 
síndromes cerebelosos de difícil recuperabilidad, habitualmente se degrada rápidamente con la Cytidine-deaminasa, expresada en hígado y riñón, pero que no es producida en el SNC, de manera que la postergación de su inactivación permitiría prolongar su presencia en el parénquima nervioso $^{8}$

También se ha especulado que el Metrotrexato tendría un potencial efecto desmielinizante sobre el SNC, debido a la inhibición que ejercería en la síntesis de S-adenosil meteonina (SAM) componente de las vainas de mielina ${ }^{9,10}$. Este posible efecto requiere de mucho tiempo que no concordaría con las mielopatías agudas, aunque se hayan comunicado mielopatías atribuidas al Metrotrexato $^{10}$.

Presentamos dos pacientes portadores de una LLA, que desarrollaron una mielopatía como complicación de la QI. En estos enfermos se pusieron en evidencia síntomas precoces del daño neurológico, permitiendo describir la evolución y comprender su patogenia.

\section{Caso 1}

Mujer de 18 años, ingresada a Hematología del Hospital del Salvador por LLA común (Philadelphia negativo). Recibió quimioterapia LLA
15-30 según el protocolo nacional (Tabla 1). La inducción produjo buena respuesta, lográndose remisión completa, seguida por la terapia de consolidación con QI (Metrotrexato $15 \mathrm{mg}$, Citarabina $50 \mathrm{mg}$ y Betametasona $4 \mathrm{mg}$ ). Al sexto mes, durante la etapa de mantención apareció cefalea y pérdida de visión. El examen neuro-oftalmológico demostró edema de papila del ojo derecho, la Resonancia Magnética (RM) engrosamiento del nervio óptico. El mielograma simultáneo $50 \%$ de linfoblastos, los síntomas oculares fueron interpretados como una recaída precoz. Se inició terapia de rescate (esquema $\mathrm{R} 1$ ), con quimioterapia intratecal triple asociada, bisemanal. Después de la segunda inoculación intratecal la paciente se quejó de parestesias en las extremidades inferiores (EEII) y de incontinencia urinaria. El examen neurológico mostró una paciente vigil, activa, con lenguaje conservado, disminución de la agudeza visual del ojo derecho, déficit propioceptivo y debilidad de EEII, reflejos osteotendíneos (ROT) presentes y Babinski bilateral. Ausencia de compromiso en extremidades superiores (EESS). La RM de la médula mostró hiperintensidad de los cordones posteriores desde cervical a lumbar e hiperintensidad de la cauda equina (Figura 1). Después de la primera semana, la paraparesia evolucionó a una paraplejia fláccida arrefléctica, apareciendo hipostesia táctil con nivel en D9. Se inició Tiamina

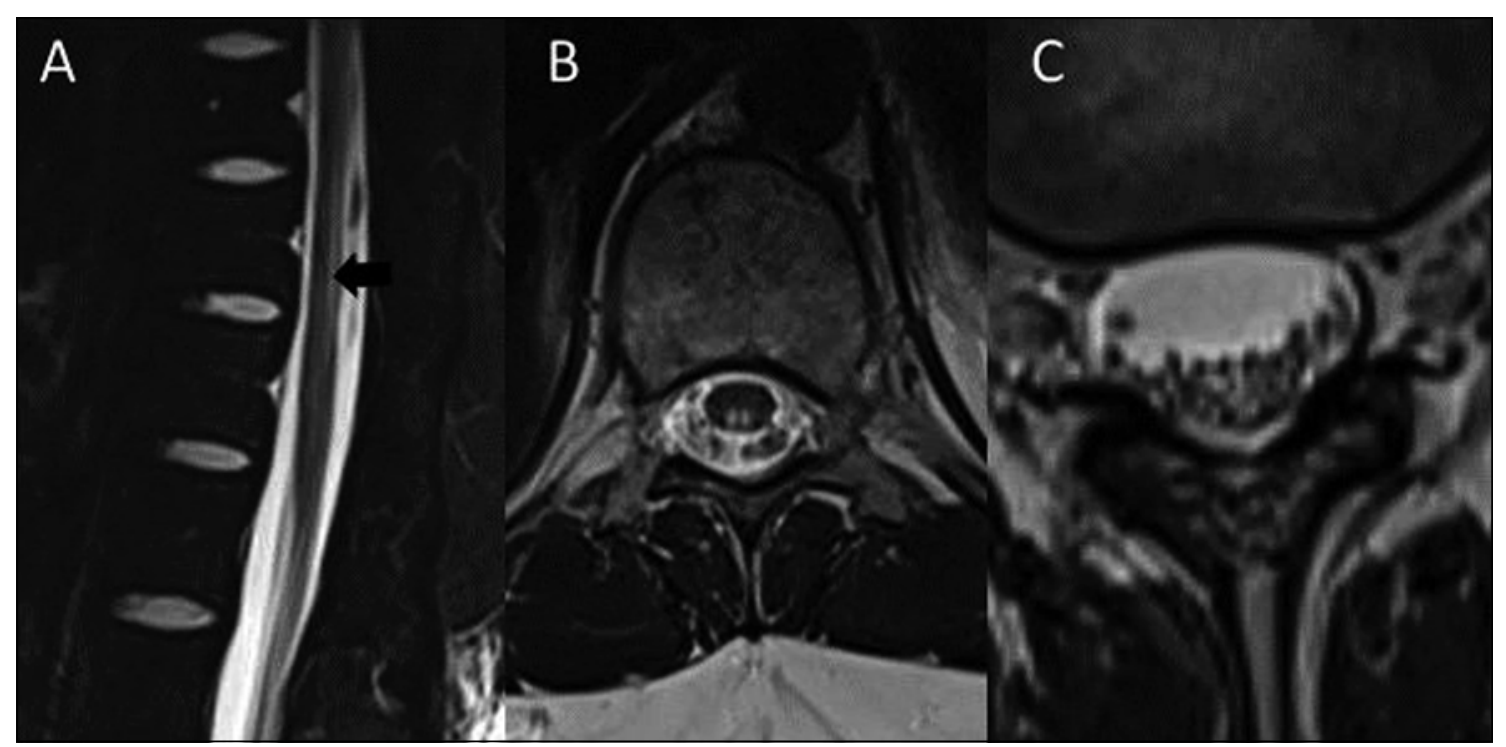

Figura 1. Paciente N1, se muestra hiperintensidad de cordones posteriores (A: sagital flecha, B: Axial dorsal), se observa además hiperintensidad en múltiples raíces de la cauda equina (C). (RM médula espinal, secuencia T2). 
$90 \mathrm{mg}$ c/12 h, Piridoxina $150 \mathrm{mg} \mathrm{c} / 12 \mathrm{~h}$, Leucovorina $50 \mathrm{mg} \mathrm{c} / 12 \mathrm{~h}$, Cianocobalamina $2 \mathrm{amp} \mathrm{c} / 24 \mathrm{~h}$, Meteonina y S-adenosylmetionina.

Al decimosexto día se definió un nivel sensitivo en D6 y los ROT estaban universalmente abolidos, aunque no presentaba alteraciones motoras ni sensitivas en extremidades superiores ni en pares craneales. En el día vigesimosexto la paciente expresó un persistente dolor urente, debilidad de ambos brazos y cefalea occipital. Se realizó Angio-TAC de cerebro que no mostró alteraciones. El LCR tenía: Prot: $0,79 \mathrm{~g} / \mathrm{L}$; Gluc: 0,57 mg/L; leucocitos: 74 por ul. La RM de la médula mostró además de la hiperintensidad de los cordones posteriores, la de los cordones laterales (Figura 2). El día trigésimotercero amaneció tetrapléjica y con disfagia, al día siguiente presentó disnea por falla respiratoria, falleciendo en la tarde.

\section{Caso 2}

Ingresa a Hematología paciente masculino de 16 años, con una LLA común, (Philadelphia negativo). Inducción con esquema LLA 15-30 según protocolo (Tabla 1), con rápida respuesta y remisión completa. En la etapa de consolidación se inició QI triple (Metrotrexato $15 \mathrm{mg}$, Citarabina $50 \mathrm{mg}$, Betametasona $4 \mathrm{mg}$ ). Durante esta etapa apareció neutropenia y el mielograma mostró 71\% de linfoblastos y presencia de blastos en LCR, sin síntomas neurológicos. Se definió como una recaída combinada precoz. En la terapia de rescate, recibió seis pulsos de QI, lográndose remisión completa y desaparición de los blastos del LCR. Al octavo mes se continuó con block R2 (Tabla 1). Después del primer procedimiento intratecal inició inestabilidad de la marcha. El examen neurológico mostró un paciente vigil, orientado, sin alteración de pares craneanos, ni de la potencia muscular, ROT preservados, marcha insegura, Romberg positivo y alteración propioceptiva en las EEII, prueba índice-nariz y talón-rodilla normales. Se suspendió quimioterapia, iniciándose Tiamina $90 \mathrm{mg} \mathrm{c} / 12 \mathrm{~h}$, Piridoxina $150 \mathrm{mg}$ c/12 h, Leucovorina $50 \mathrm{mg} \mathrm{c} / 12 \mathrm{~h}$, Cianocobalamina 2 ampollas $\mathrm{y}$ c/24 h Meteonina S-adenosylmetionina.

Dos días después paciente vigil con funciones

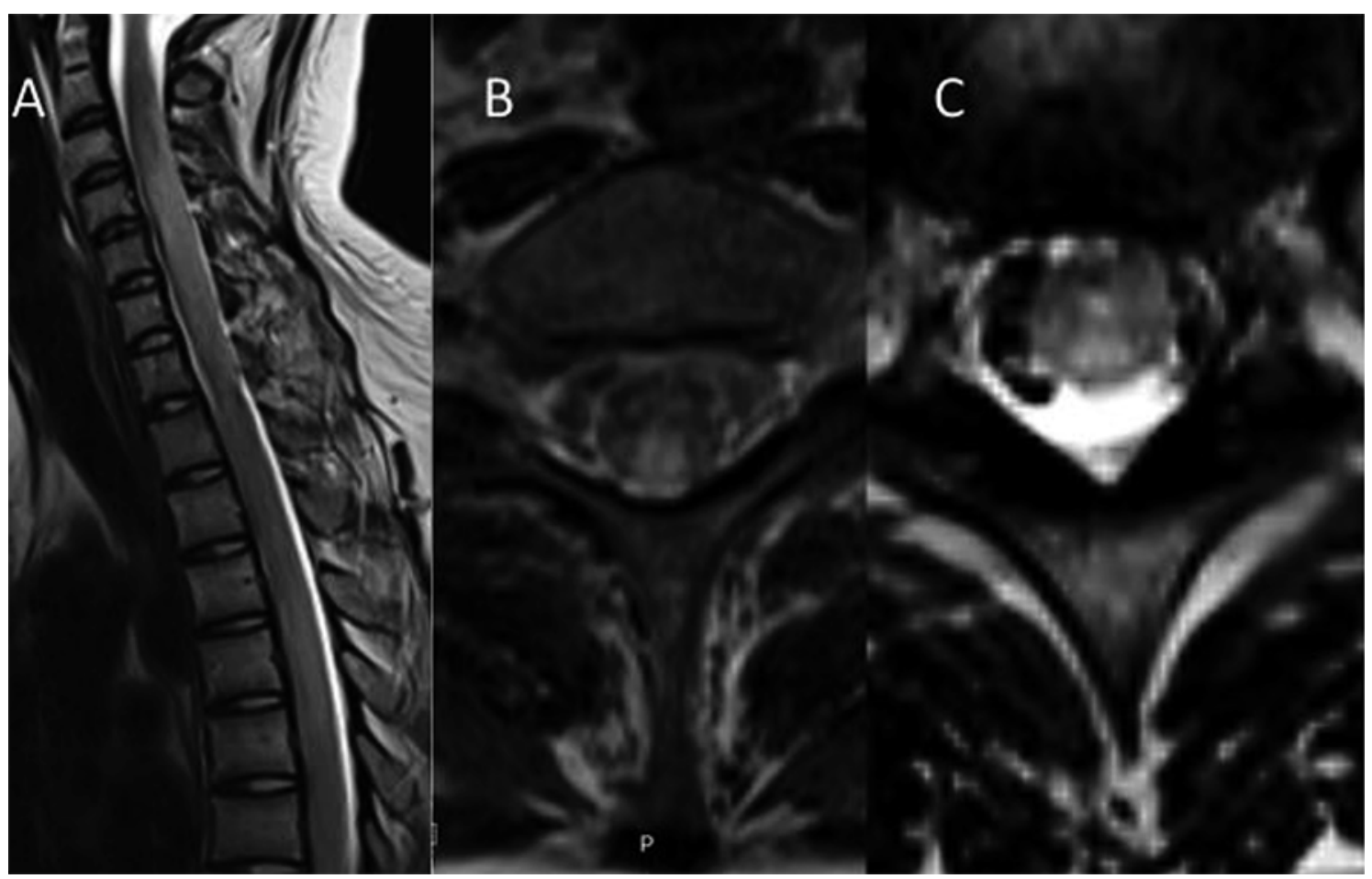

Figura 2. RM médula espinal, secuencia $T 2$ Paciente N1, se muestra extenso compromiso medular en corte sagital, imágenes axiales muestra hiperintensidad cordones posteriores y laterales (B: nivel C5-C6; C: nivel D8). 
Degeneración de médula espinal y radiculopatía - L. Cartier et al

Tabla 1. Protocolo nacional PANDA

\section{Inducción}

Quimioterapia intratecal triple (Metotrexato $15 \mathrm{mg}$, Citarabina 50 mg, Betametasona $4 \mathrm{mg}$ ) día 8 y 29

Dexametasona $10 \mathrm{mg} / \mathrm{m}^{2} / \mathrm{día}$, IV, días 1 al 14

Vincristina 1,5 mg/m²/día, IV, (dosis máx $2 \mathrm{mg}$ ), días 1, 8, 15, 22

Daunorrubicina $25 \mathrm{mg} / \mathrm{m}^{2} /$ día, IV, días $1,8,15,22$

L-asparaginasa **6.000 U/m², IM, días 15, 17, 19, 22, 24, 26 y 29

\section{Reinducción}

Dexametasona $10 \mathrm{mg} / \mathrm{m}^{2} /$ día, IV, días 1 al 7

Vincristina $1,5 \mathrm{mg} / \mathrm{m}^{2} /$ día, IV (dosis máx $2 \mathrm{mg}$ ), días 1 y 8

Daunorrubicina $25 \mathrm{mg} / \mathrm{m}^{2} / \mathrm{día}$, IV, día 1

L-asparaginasa ${ }^{* *} 6.000 \mathrm{U} / \mathrm{m}^{2}, \mathrm{IM}$, días 1,3 y 5

\section{Consolidación}

Quimioterapia intratecal triple (Metotrexato $15 \mathrm{mg}$, Citarabina $50 \mathrm{mg}$, Betametasona $4 \mathrm{mg}$ ) días 1, 8, 15 y 22

6-Mercaptopurina $60 \mathrm{mg} / \mathrm{m}^{2} / \mathrm{día}$, VO, días 1-14 y 29-42

Ciclofosfamida **1.000 mg/m²/día,IV, días 1 y 29

Citarabina *75 mg/m²/día IV, por 4 días cada vez, días 1-4, 8-11, 29-32, 36-39

Vincristina $1,5 \mathrm{mg} / \mathrm{m}^{2} /$ día, IV (dosis máx $2 \mathrm{mg}$ ), días $15,22,43$ y 50

L-asparaginasa **6.000U/m², IM, días $15,17,19$ y 43, 45, 47

\section{Mantención interina I}

Quimioterapia intratecal triple (Metotrexato 15 mg, Citarabina 50 mg, Betametasona $4 \mathrm{mg}$ ) día 1 y 29

6-Mercaptopurina $25 \mathrm{mg} / \mathrm{m}^{2} /$ día, VO días 1 AL 56

Metotrexato**2.000 mg/m², IV días $1,15,29,43$

Vincristina 1,5 mg/m²/día IV (dosis máx $2 \mathrm{mg}$ ), días 1, 15, 29 y 43

\section{Intensificación tardía I}

Quimioterapia intratecal triple (Metotrexato 15 mg, Citarabina 50 mg, Betametasona 4 mg) día 1, 29 y 36

Dexametasona $10 \mathrm{mg} / \mathrm{m}^{2}$, VO, días 1 al 7 y 15 al 21

Vincristina 1,5 mg/m²/día, IV, (dosis máx $2 \mathrm{mg}$ ) días 1, 8, 15, 43, 50

Doxorrubicina * $25 \mathrm{mg} / \mathrm{m}^{2} /$ día, IV, días 1,8 y 15

L-asparaginasa $6.000 \mathrm{U} / \mathrm{m}^{2}, \mathrm{IM}$, días $4,6,8,43,45$ y 47

Ciclofosfamida $1.000 \mathrm{mg} / \mathrm{m}^{2} /$ día, IV, día 29

Citarabina $75 \mathrm{~g} / \mathrm{m}^{2} /$ día, IV, por 4 días cada vez, días 29 al 32 y 36 al 39

Tioguanina $60 \mathrm{mg} / \mathrm{m}^{2} /$ día, VO, días 29 al 42

\section{Mantención interina II}

Quimioterapia intratecal triple (Metotrexato $15 \mathrm{mg}$, Citarabina $50 \mathrm{mg}$, Betametasona $4 \mathrm{mg}$ ) día 1 y 31

Vincristina 1,5 mg/m/día, IV, (dosis máx $2 \mathrm{mg}$ ) días 1, 11, 21, 31 y 41

Metotrexato $100 \mathrm{mg} / \mathrm{m}^{2}$, IV días 1, 11, 21, 31 y 41

L-asparaginasa $6.000 \mathrm{U} / \mathrm{m}^{2}, \mathrm{IM}$, días 1, 3, 5, y 21, 23, 25

\section{Mantención (2 años mujeres, 3 años varones)}

Mercaptopurina $75 \mathrm{mg} / \mathrm{m}^{2} /$ día, vo, Todos los días

Methotrexato $20 \mathrm{mg} / \mathrm{m}^{2} /$ día, vo, 1 día a la semana

Vincristina $1,5 \mathrm{mg} / \mathrm{m}^{2} /$ día, IV, (dosis máx $2 \mathrm{mg}$ ), 1 mensual

Dexametasona $6 \mathrm{mg} / \mathrm{m}^{2}$; VO, Mensual, días 1 al 5

Quimioterapia intratecal triple (Metotrexato $15 \mathrm{mg}$, Citarabina $50 \mathrm{mg}$, Betametasona $4 \mathrm{mg}$ ) trimestral $\times 4$ veces

superiores preservadas, había progresado la inestabilidad de la marcha, agregándose hipostesia táctil, dificultad para la bipedestación por debilidad proximal de EEII, hiperreflexia, Babinski e incontinencia urinaria. RM de médula mostró aumento de señal en cordones posteriores desde cervical a T11 (Figura 3).
Al sexto día aumentó la debilidad en EEII y pared abdominal, ROT apagados, Babinski, las alteraciones propioceptivas persistían, tenía preservada la sensibilidad dolorosa, sin compromiso en EESS. En el día decimosegundo tenía paraplejia fláccida, ROT abolidos, sin nivel sensitivo. Un hemograma con recaída leucémica en el día decimo- 


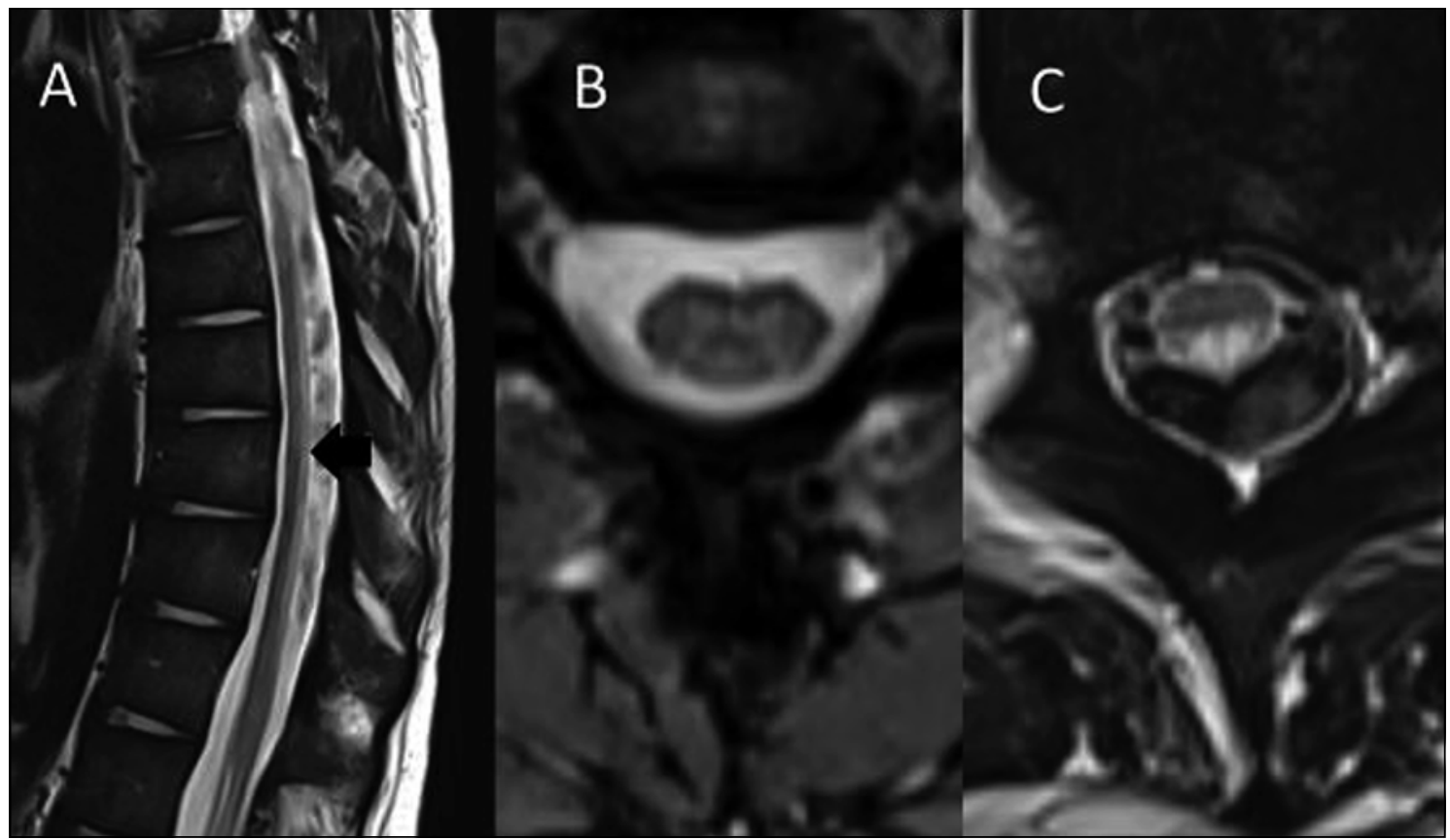

Figura 3. RM médula espinal paciente 2 , en T2 se observa hiperintensidad de cordones posteriores en segmentos cervical C6 (B) y dorsal T10 (C).

nono obligó a continuar con cuidados paliativos en su domicilio. El compromiso neurológico no progresó, falleciendo de la LLA.

\section{Comentario}

El daño de las vías propioceptivas (cordones posteriores) y las vías motoras (cordones laterales) definen el síndrome de degeneración combinada de la médula por déficit de vitamina B12 y Ácido Fólico, alteración semejante se observa en la Mielopatía Espongiforme del SIDA, la Paraparesia Espástica Tropical ambas de etiología retroviral ${ }^{11}$ y en las mielopatías tóxicas producidas por la QI.

En veintiocho casos de compromiso mielorradicular comunicados hasta los años ochenta, originados por el uso QI. Kwong y colaboradores encontraron que este daño debutó entre uno y noventa días después de la QI, estableciendo que 75\% de los casos se inició antes del cuarto día. El 82\% desarrolló una paraplejia, $11 \%$ una cuadriplejia y $7 \%$ sólo compromiso radicular ${ }^{4}$. La precocidad en el desarrollo del daño después de la inoculación intratecal es sugerente de una mielopatía tóxica, como Breuer y colaboradores han sostenido basados en el paciente que estudiaron, que usó sólo Citarabina, su neuropatología mostró compromiso axonal primario expresado en la vacuolización $y$ engrosamiento de los axones, presente a distal en cordón posterior desde la región cervical y en cordón lateral desde la región lumbar. Este daño axonal originó una natural desmielinización, génesis de la mielopatía espongiforme ${ }^{12}$. Este compromiso tan específico de los largos axones sensitivos y motores permitió a Satomi definir su caso como un síndrome de degeneración combinada, basado sólo en el estudio neuropatológico de su paciente 5 . Clark comunicó su caso como degeneración combinada de la médula, aunque clínicamente era una paraplejia espástica, porque la neuropatología encontró engrosamiento y dilatación de los axones en haces propioceptivos como motores ${ }^{13}$. El paciente con paraplejia fláccida que estudió Murata y colaboradores fue comparado con otros cinco casos, publicados recientemente, cuyos estudios con Resonancia Magnética permitió observar que los seis tenían hiperintensidad de los cordónes posteriores como nuestros pacientes, y cuatro tenían además hiperintensidad de los 
cordones laterales, como la paciente N1. Además, esos seis pacientes tenían estudió de vitamina B12 y ácido fólico normales, que permitirían descartar efectos del Metrotrexato, aunque igualmente fueron tratados sin resultados con el mismo esquema vitamínico que nosotros usamos ${ }^{6}$.

Los dos pacientes son comparables clínica e imagenológicamente a los casos comunicados. El seguimiento realizado en ellos nos permitió identificar la evolución clínica. Primero desarrollaron un compromiso del cordón posterior y con leve latencia del cordón lateral, semanas después se asoció el compromiso radicular (abolición de los ROT). La rápida y selectiva alteración de determinados axones del parénquima medular sólo se explican por un daño axonal primario, axonopatía central por bloqueo del transporte axoplásmico, que inicialmente es funcional luego degenerativa y desmielinizante. El tardío compromiso radicular, se entiende por la distinta estructura y condición metabólica de las raíces. Daño radicular que no es excepcional, basado en las frecuentes paraplejias fláccidas descritas.

Finalmente, la paciente N1, que inició sus molestias con disminución de la agudeza visual por edema de papila, estaba expresando un conocido efecto tóxico de la Citarabina sobre el nervio óptico, efecto que suele ser benigno. Sus características han sido descritas e interpretadas como un síndrome de pseudo-tumor cerebral por algunos autores ${ }^{14}$. En ella se pudo vislumbrar la susceptibilidad a la Citarabina.

\section{Referencias}

1. Puga B, Guerra C, Molina J, Cabrera M, Pilleux L, Calderón S, et al. Leucemia linfoblástica aguda estirpe B Philadelphia negativa en adolescentes y adultos jóvenes. Resultados del Protocolo Terapéutico LLA 15-30, Programa Nacional de Cáncer del Adulto (PANDA), Ministerio de Salud, Chile. Rev Med Chile 2014; 142: 707-15.

2. Alsdorf W, Schmitz M, Schieferdecker A, Dierlamm J, Bokemeyer C, Binder M. Severe and irreversible myelopathy after concurrent systemic and intrathecal nucleoside analogue treatment for refractory diffuse large B-cell lymphoma: A case report and review of the literature. Oncol Pharm Practice 2016; 22 (3): 523-7.

3. Burch P, Grossman S, Reinhard C. Spinal Cord Penetration of Intrathecally Administered Cytarabine and Methotrexate. A Quantitative Autoradiographic Study. Journal of the National Cancer Institute 1988; 80: 15.

4. Kwong Y, Yeung D, Chan J. Intrathecal chemotherapy for hematologic malignancies: drugs and toxicities. Ann Hematol 2009; 88: 193-201.

5. Satomi K, Yoshida M, Matsuoka K, Okita H, Hosoya Y, Shioda Y, et al. Myelopathy mimicking subacute combined degeneration in a Down syndrome patient with methotrexate treatment for B lymphoblastic leukemia: Report of an autopsy case. Neuropathology 2014; 34: 414-9.

6. Murata K, Maeba A, Yamanegi M, Nakanishi I, Ito H. Methotrexate myelopathy after intrathecal chemotherapy: a case report. Journal of Medical Case Reports 2015; 9: 135 . 